\title{
Substance use and dietary practices among students attending alternative high schools: results from a pilot study
}

\author{
Chrisa Arcan ${ }^{1 *}$, Martha Y Kubik², Jayne A Fulkerson², Peter J Hannan and Mary Story
}

\begin{abstract}
Background: Substance use and poor dietary practices are prevalent among adolescents. The purpose of this study was to examine frequency of substance use and associations between cigarette, alcohol and marijuana use and selected dietary practices, such as sugar-sweetened beverages, high-fat foods, fruits and vegetables, and frequency of fast food restaurant use among alternative high school students. Associations between multisubstance use and the same dietary practices were also examined.
\end{abstract}

Methods: A convenience sample of adolescents ( $n=145 ; 61 \%$ minority, 52\% male) attending six alternative high schools in the St Paul/Minneapolis metropolitan area completed baseline surveys. Students were participants in the Team COOL (Controlling Overweight and Obesity for Life) pilot study, a group randomized obesity prevention pilot trial. Mixed model multivariate analyses procedures were used to assess associations of interest.

Results: Daily cigarette smoking was reported by $36 \%$ of students. Cigarette smoking was positively associated with consumption of regular soda $(p=0.019)$, high-fat foods $(p=0.037)$, and fast food restaurant use $(p=0.002)$. Alcohol ( $p=0.005)$ and marijuana use $(p=0.035)$ were positively associated with high-fat food intake. With increasing numbers of substances, a positive trend was observed in high-fat food intake $(p=0.0003)$. There were no significant associations between substance use and fruit and vegetable intake.

Conclusions: Alternative high school students who use individual substances as well as multiple substances may be at high risk of unhealthful dietary practices. Comprehensive health interventions in alternative high schools have the potential of reducing health-compromising behaviors that are prevalent among this group of students. This study adds to the limited research examining substance use and diet among at-risk youth.

Trial registration number: ClinicalTrials.gov: NCT01315743

\section{Background}

Substance use and poor dietary practices are prevalent among adolescents $[1,2]$. In the general population, substance abuse is strongly correlated with violent behavior, weapon carrying in school, motor vehicle accidents, unintended pregnancy, and HIV [3-9], which are the leading causes of morbidity and mortality in youth. Recent national data indicate that almost one half of adolescents have smoked cigarettes [1] in their lifetime. Among $12^{\text {th }}$ grade students, about $42 \%$ have tried

\footnotetext{
* Correspondence: arca0021@umn.edu

'University of Minnesota, Division of Epidemiology and Community Health, School of, Public Health, 1300 South 2nd Street, Suite 300, Minneapolis, MN 55454, USA

Full list of author information is available at the end of the article
}

marijuana and almost three out of four consumed alcohol in their lifetime [2].

An unhealthful diet can compound the health effects of substance use, since poor diet and substance use are independent risk factors for chronic diseases, such as atherosclerosis and some cancers [10-12]. The majority of adolescents do not have diets that follow the Dietary Guidelines for Americans; close to $80 \%$ of adolescents do not consume the daily recommended servings of fruits and vegetables and one third consume regular soda at least one time a day [1]. Observational studies have often found covariation of health risk behaviors among both adolescents [13-17] and adults [15,18-20]. Research on correlations of individual substances and 
eating behaviors indicates that smoking is associated with greater consumption of fat [21], soft drinks [16], and fast food [22] and with lower consumption of fruits and vegetables [22-25]; alcohol is associated with fat intake [21].

Most studies assessing correlations between substance use and dietary behaviors have done so in traditional high schools $[13,21,22,26]$. Factor analysis guiding the identification of clusters of behaviors among a large sample of adolescents indicates that adolescents engaging in risk-seeking behaviors, such as tobacco, alcohol and marijuana use have almost twice the odds ratio of unhealthy eating [13]. In a large sample of diverse middle and high school students, smoking frequency was directly related to frequency of fast food consumption and inversely related to regular breakfast, lunch, and dinner consumption [22]. A study by Burk and colleagues examining substance use, physical activity and diet in a sample of 18 year old male and female students found clustering of unhealthy behaviors; both males and females who smoked engaged in unsafe drinking and females had low levels of fiber whereas males had high fat intake [21].

Research shows that at-risk youth who use substances are more likely to be involved in violent behavior, dropout of school, truancy, and engage in multiple health behaviors [27-30]. One group of adolescents who are atrisk of dropping out of school [31] and are likely to be involved in high-risk behaviors are students who attend alternative high schools. Alternative high schools are more common in urban districts, and roughly two-thirds (62\%) of schools enroll more than $50 \%$ of minorities and close to one-half enroll greater than $20 \%$ of students below the poverty line [31]. A study examining correlations between cigarette smoking and various socioeconomic status (SES) indicators in middle and high school students found that students who attend schools with high percentages of participation in the reduced/low cost lunch program have almost 6 times the odds of smoking than students in schools with low participation in the reduced/low cost lunch program [32]. Previous studies have shown that when compared to traditional high school students, a higher percentage of alternative high students ever tried a substance; currently use substances; and drive under the influence of alcohol $[14,33]$. A study using national data of alternative high school students found close to one in five students having used multiple substances on school property [33]. A study in a Texas district found $77 \%$ of males in an alternative school compared to $20 \%$ in a traditional school to have smoked at least one cigarette in the past month. The same study found $85 \%$ and $88 \%$ of alternative school males and females, respectively reported having five drinks at one time on at least one occasion in the past month, compared to $55 \%$ and $34 \%$ of males and females in traditional schools [34]. Recent studies have also indicated a high prevalence of overweight and obesity, unhealthful diet, and low physical activity levels among alternative high school students [35-37]. However, to our knowledge, no studies to date have examined correlations between substance use and dietary behaviors among alternative high school students.

Substance abuse, tobacco use and nutrition and overweight are three of the twenty eight focus areas that are addressed by Healthy People 2010 agenda to reach the goal of increasing quality and years of healthy life [9]. Thus, in order to develop comprehensive health education programs and to achieve improved health and longevity, examining correlates of substance use and dietary practices among adolescents is essential. The present study was guided by the ecological model [38] and its goals were to: 1) examine frequency of substance use among a high risk group of youth; 2) assess correlations between cigarette, alcohol, and marijuana use and dietary practices, such as consumption of regular soda, sports drinks, other-sugar sweetened beverages, high-fat foods, fruits and vegetables, and fast food restaurant use; and 3) assess correlations between multi-substance use and the same dietary practices. All analyses were conducted with students attending alternative high schools, a high-risk group of youth.

\section{Methods}

\section{Study Design and Sample}

The present study used a cross-sectional design to examine baseline data from the Team COOL (Controlling Overweight and Obesity for Life) pilot study, a multi-component diet and physical activity intervention trial to promote healthy weight loss or prevent excess weight gain among alternative high school students. Six alternative public high schools (four urban and two suburban) in the St. Paul-Minneapolis, Minnesota were contacted and agreed to participate. The data were collected in fall 2006 before schools were randomized to intervention and control conditions. Additional details about the study design are described elsewhere [39].

Student enrollment across schools varied from 27 to 142 students (mean: 102 students), with an average age of 17.3 years (range: 14.1-19.8 years). All students enrolled in the schools were eligible and were invited to participate in study measurements. Students who were younger than 18 years were given parental consent forms. On the day of measurement, trained study staff collected assents from all students and the signed parental consents from those younger than 18 years old. The students completed a 76-item survey that took about 30 to 40 minutes. The students who completed the survey had their height/weight measured and received a $\$ 5$ gift 
card. Across the six schools, a total of 145 students participated in the baseline data collection. There was a high percentage of minority students (including all races except white; mean $=64 \%$ : range $=31 \%$ to $96 \%$ ) and students receiving free/low-cost lunch (mean $=61 \%$ : range $=40 \%$ to $96 \%$ ). All study procedures were approved by the University of Minnesota's Institutional Review Board Human Subjects Committee. Due to the variable nature of student attendance in alternative high schools, the study participation rate was derived by multiplying the prior year's (2005-2006) attendance rate with the schools' 2006-2007 student enrollment [40], to give an estimated average adjusted enrollment of 68 students (range: 16 to 107). The participation rate across schools was $36 \%$ (range: $18 \%$ to $100 \%$ ).

\section{Measures}

The following dependent and independent variables were examined in this study.

\section{Dependent Variables \\ Regular soda, sports drinks and other sugar-sweetened beverage consumption}

Regular soda, sports drinks and other sugar-sweetened beverages (kool-aid, fruit drinks, lemonade or energy drinks) were assessed by asking participants to report frequency of consumption of each type of beverage over the past month [41]. Ten response categories ranged from 'Never' to ' 5 or more times a day.' For each beverage, data were recoded to times per week and modeled as a continuous variable. Higher values indicated more times per week a beverage was consumed.

\section{Fast food restaurant use}

Frequency of fast food restaurant use was assessed with the question [42], "Outside of the school day, during a normal week (including weekend days), how many times do you eat or drink something from a fast food restaurant, like McDonald's, Taco Bell or Pizza Hut?" Six response categories ranged from 'Never' to 'More than 7 times.' The data were recoded to represent times per week and modeled as a continuous variable. Higher values indicated more times a week of eating or drinking something from a fast food restaurant.

\section{High-fat food intake}

The 17-item fat screener developed by Block and colleagues and validated in an adult population was used to assess high-fat food intake [43]. Due to the older average age of the adolescents in this study, the screener was deemed appropriate for use. Examples of high-fat food items included various meats, hot dogs, fried chicken, pizza, whole milk and cheese, French fries, and doughnuts. Five response categories ranged from ' 1 time a month or less' to ' 5 or more times a week.' The data were recoded to represent times a week and modeled as a continuous variable. The Cronbach's alpha for the study sample was 0.89 . Students whose responses were greater than 3 standard deviations (SD) from the mean were excluded from the analysis $(n=2)$. Higher values indicated more times a week of high-fat food consumption.

\section{Fruit and vegetable intake}

Intake of fruits and vegetables was assessed with the 6item fruit and vegetable screener [44]. The screener was previously validated in a racially and socioeconomically diverse sample of urban high school students [44]. The items included $100 \%$ fruit juice, fruits, vegetables, green salad, potatoes (excluding French fries), and carrots. Six response categories ranged from 'Less than once a week' to '5 or more times a day.' Data were recoded as daily servings and modeled as a continuous variable. The Cronbach's alpha for the study sample was 0.85 . Students whose responses were greater than 3 SDs from the mean were excluded from the analysis $(n=2)$. Higher values indicated more servings per day of fruit and vegetable consumption.

\section{Independent Variables \\ Substance Use}

A single item adopted from the Youth Risk Behavior Surveillance System (YRBSS) was used to measure frequency of substance use [45]. Students were asked to report how often they used the following substances during the past year: a) cigarettes, b) beer, wine, hard liquor, c) marijuana, and d) drugs other than marijuana (acid, cocaine, etc). In the current study, only the first three categories were used since the majority of students reported never having used drugs other than marijuana. The measure demonstrated good reliability [45] and has been used in other studies with adolescents [22]. The response categories were 'never', 'a few times', 'monthly', 'weekly', or 'daily.' To describe frequency of substance use, the categories were collapsed to 'never', 'frequent, but not daily use', and 'daily use.'

To examine associations between frequency of each substance and dietary practices, each substance was used as a continuous variable. We also examined associations between multi-substance use and dietary behaviors. The multi-substance use variable was created by first dichotomizing the original responses of each substance to 'never' or 'ever' having used each substance during the past year. A four-category multi-substance use variable was then created by summing the newly created dichotomized substance use variables (cigarette, alcohol, and marijuana). The four categories representing multi-substance use in the past year included: 1 ) never used any substance, 2) used any one substance, 3) used any two substances, and 4) used all three substances. We also assessed the overall impact of 
substance use on diet quality by treating the six dietary behaviors as correlated outcomes within individual. The repeated measures analysis of the six dietary behaviors estimated a single association of substance use on the overall diet quality. All sugar-sweetened beverages, highfat food, and fast food restaurant use were reverse coded to represent a healthful diet quality.

\section{Demographic Characteristics}

Gender, age, race/ethnicity and SES were included in the models as potential confounders. Age and gender were obtained from school records; age was modeled as a continuous variable. Students reported their race/ethnicity and categories included: a) American Indian or Alaskan Native, b) Asian (including Cambodian, Hmong, Korean, Laotian, and Vietnamese), c) Black or African American, d) Hispanic or Latino, e) White, and f) Other." To ensure adequate sample size for analyses, the categories were collapsed to White, Black and other. The 'other' racial/ethnic category included the following groups: American Indian or Alaskan Native (1\%); Asian, including Cambodian, Hmong, Korean, Laotian, and Vietnamese (6\%); Hispanic or Latino (9\%); multi-ethnic non-Hispanic (10\%); other (3\%). For most students, SES was measured with the question "Do you get free/lowcost lunches at school?" $(\mathrm{n}=135)$. Response categories were 'Yes', 'No', and 'I don't know.' If the response was missing or 'I don't know,' the question 'Does your family get public assistance (welfare, food stamps or other assistance?) was used $(n=8)$ [46]. A 'Yes' response indicated lower SES and a 'No' response indicated higher SES.

\section{Statistical Analysis}

Descriptive statistics were used to assess the frequency of cigarette smoking, alcohol and marijuana use and the frequency of multi-substance use by demographic characteristics in our sample of alternative high school students. Chi-square and t-tests were used to test bivariate associations between substance use and demographic characteristics. Mixed model analysis of variance was used to assess the association between each substance and each dietary practice. Mixed model analysis of variance was also used to examine associations between multi-substance use (four-category variable) and dietary practices. Separate analyses were conducted for each dietary practice, and each analysis was controlled for gender, race/ethnicity, age, and SES.

Since student intake of each type of sugar-sweetened beverage and fruits and vegetables were positively skewed, they were square-root transformed in all mixed model analyses when determining statistical significance. The square-root transformed variables are approximately Gaussian distributed, thus the p-values using the transformed variables are more accurate since they are dependent on the tails of the distribution. However for ease of interpretation, the presentation of mean servings was generated on the natural scale (untransformed). The school variable was included in the model as a random effect, accounting for the additional component of variance associated with a cluster sampling design where observations from students from the same schools may be correlated [47]. PROC MIXED procedures were utilized since the outcome variables were continuous. The level of significance was set at two-sided $\mathrm{p}<0.05$.

\section{Results}

Table 1 shows frequencies of each substance used by socio-demographic characteristics. Overall, $36 \%$ of students reported daily use of cigarettes, $13 \%$ marijuana and $3 \%$ alcohol. Females and males reported equal percentages of daily cigarette (36\%) and marijuana (13\%) use. White students and those in higher SES had higher daily consumption of each substance compared to their counterparts. Table 2 depicts frequency of multi-substance use by socio-demographic characteristics. Overall, $79 \%$ of the students used at least one substance and almost onethird used all three substances in the past year.

Table 3 presents the results of the multivariate models assessing associations between each substance and each dietary practice, adjusted for potential confounders. Cigarette smoking was positively associated with consumption of regular soda $(\mathrm{p}=0.019)$, high-fat foods ( $\mathrm{p}$ $=0.037)$, and fast food restaurant use $(\mathrm{p}=0.002)$. For example, higher use of cigarette smoking was associated with an additional weekly consumption of 1.22 times of regular soda. Alcohol use $(\mathrm{p}=0.005)$ and marijuana use $(\mathrm{p}=0.035)$ were positively associated with high-fat food consumption. All other estimated associations were statistically non-significant at the $\mathrm{p}<0.05$.

Table 4 presents adjusted means of dietary practices by categories of multi-substance use. Multi-substance use was significantly associated with high-fat food intake $(\mathrm{p}=0.0003)$. Students who used all three substances over the past year consumed high-fat foods 11 additional times per week than students who never used any substance. Also, those who used any one substance or any two substances had additional weekly consumption of 12 and 7 times of high-fat foods, respectively, compared to those who never used any substance ( $\mathrm{p}$-value for trend $=0.002$ ). Regular soda consumption and multi-substance use were marginally positively associated $(\mathrm{p}=0.058)$. Specifically, there was an additional weekly consumption of 5.4 times of regular soda between those who used all three substances and those who did not use any substance in the past year ( $\mathrm{p}$-value for trend $=0.008$ ). There were no significant associations between categories of multi-substance use and fruit and vegetable intake. 
Table 1 Frequency of substance use among alternative high school students by demographic characteristics in the past 12 months $(n=145)^{\mathrm{a}}$

\begin{tabular}{|c|c|c|c|c|c|c|c|c|c|}
\hline \multirow[b]{2}{*}{$\begin{array}{l}\text { Demographic } \\
\text { Characteristics }\end{array}$} & \multicolumn{3}{|c|}{ Cigarette Smoking } & \multicolumn{3}{|c|}{ Alcohol Use } & \multicolumn{3}{|c|}{ Marijuana Use } \\
\hline & $\begin{array}{l}\text { Never } \\
\text { n (\%) }\end{array}$ & $\begin{array}{c}\text { Frequent, but } \\
\text { not daily use } \\
n(\%)\end{array}$ & $\begin{array}{c}\text { Daily use } \\
\text { n (\%) }\end{array}$ & $\begin{array}{l}\text { Never } \\
\text { n (\%) }\end{array}$ & $\begin{array}{l}\text { Frequent, but } \\
\text { not daily use } \\
\text { n (\%) }\end{array}$ & $\begin{array}{l}\text { Daily use } \\
\text { n (\%) }\end{array}$ & $\begin{array}{l}\text { Never } \\
\text { n (\%) }\end{array}$ & $\begin{array}{l}\text { Frequent, but } \\
\text { not daily use } \\
\text { n (\%) }\end{array}$ & $\begin{array}{c}\text { Daily use } \\
\text { n (\%) }\end{array}$ \\
\hline Total $(N=145)$ & $60(42 \%)$ & $32(22 \%)$ & $52(36 \%)$ & $60(42 \%)$ & $80(55 \%)$ & $4(3 \%)$ & 74 (51\%) & $52(36 \%)$ & $19(13 \%)$ \\
\hline Gender & & $(n=144)$ & & & $(n=144)$ & & & $(n=145)$ & \\
\hline Male & $33(44 \%)$ & $15(20 \%)$ & 27 (36\%) & 29 (39\%) & $43(57 \%)$ & $3(4 \%)$ & $38(50 \%)$ & $28(37 \%)$ & $10(13 \%)$ \\
\hline Female & 27 (39\%) & $17(25 \%)$ & $25(36 \%)$ & $31(45 \%)$ & $37(54 \%)$ & $1(1 \%)$ & $36(52 \%)$ & $24(35 \%)$ & $9(13 \%)$ \\
\hline Race & & $(n=144)$ & & & $(n=144)$ & & & $(n=145)$ & \\
\hline Black & $26(58 \%)$ & $11(24 \%)$ & $8(18 \%)$ & $27(60 \%)$ & 17 (38\%) & $1(2 \%)$ & $24(52 \%)$ & $14(30 \%)$ & $8(14 \%)$ \\
\hline White & $16(28 \%)$ & $11(19 \%)$ & 30 (53\%) & $16(28 \%)$ & $39(68 \%)$ & $2(4 \%)$ & $28(49 \%)$ & $21(37 \%)$ & $8(17 \%)$ \\
\hline Other & $18(43 \%)$ & $10(24 \%)$ & $14(33 \%)$ & 17 (41\%) & $24(57 \%)$ & $1(2 \%)$ & $22(52 \%)$ & $17(40 \%)$ & $3(7 \%)$ \\
\hline SES & & $(n=142)$ & & & $(n=142)$ & & & $(n=143)$ & \\
\hline Higher & $16(31 \%)$ & $11(22 \%)$ & $24(47 \%)$ & 17 (33\%) & $32(63 \%)$ & $2(4 \%)$ & $24(46 \%)$ & $20(38 \%)$ & $8(15 \%)$ \\
\hline Lower & $42(46 \%)$ & $21(23 \%)$ & $28(31 \%)$ & $41(45 \%)$ & $48(53 \%)$ & $2(2 \%)$ & 48 (53\%) & $32(35 \%)$ & $11(12 \%)$ \\
\hline Age & & $(n=144)$ & & & $(n=144)$ & & & $(n=145)$ & \\
\hline Mean (SD) & $16.9(1.3)$ & $17.4(1.1)$ & $17.4(0.97)$ & $16.8(1.2)$ & $17.5(1.0)$ & $17.7(0.63)$ & $17.1(1.2)$ & $17.4(1.0)$ & $17.1(1.2)$ \\
\hline
\end{tabular}

${ }^{a}$ Cases in each analysis ranged from 142-145 due to incidental missing data. 'Frequent but not daily use' indicates those who reported using a substance at least few times in the past 12 months but less often than daily; 'daily use' indicate those who reported using a substance daily

The correlation matrix between the components (dietary practices) of the diet revealed highest correlations between fast food restaurant use and high-fat food intake (0.658) and between sports drinks and other sugar-sweetened beverages (0.595). Consumption of fruits and vegetables were negatively correlated with sports drinks, other sugar-sweetened beverages, high-fat food, and fast food restaurant use (Table 5). There was a significant association $(\mathrm{p}=0.010)$ between multi- substance use and overall diet quality averaged over the six components of the diet. The least squares means and differences indicated that the category of 'no substance use' was positively associated with a diet quality (beta $=0.224$ ) indicating that never having used any substance was related to a healthful diet, including higher intake of fruits and vegetables, and lower intake of sugar-sweetened beverages, high fat foods, and fast food restaurant use. In contrast, any other category of

Table 2 Multi-substance use among alternative high school students by socio-demographic characteristic in the past 12 months

\begin{tabular}{|c|c|c|c|c|c|}
\hline \multirow[b]{2}{*}{ Demographic Characteristics } & \multicolumn{5}{|c|}{ Number of Substances Used in the Past 12 Months ${ }^{a}$} \\
\hline & $\begin{array}{c}\text { Never Used Any } \\
\mathrm{n}(\%)\end{array}$ & $\begin{array}{c}\text { Used any one } \\
n(\%)\end{array}$ & $\begin{array}{c}\text { Used any two } \\
n(\%)\end{array}$ & $\begin{array}{c}\text { Used all three } \\
\mathrm{n}(\%)\end{array}$ & P-Value \\
\hline Total $(n=145)$ & $31(21 \%)$ & $33(23 \%)$ & $37(26 \%)$ & $44(30 \%)$ & \\
\hline \multicolumn{6}{|l|}{ Gender } \\
\hline Male $(n=76)$ & $17(22 \%)$ & $18(24 \%)$ & $15(20 \%)$ & $26(34 \%)$ & $0.389^{b}$ \\
\hline Female $(n=69)$ & $14(20 \%)$ & $15(22 \%)$ & $22(32 \%)$ & $18(26 \%)$ & \\
\hline \multicolumn{6}{|l|}{ Race/Ethnicity } \\
\hline White $(\mathrm{n}=57)$ & $8(14 \%)$ & $10(18 \%)$ & $16(28 \%)$ & $23(40 \%)$ & $0.095^{b}$ \\
\hline Black $(n=46)$ & $14(31 \%)$ & $12(26 \%)$ & $13(28 \%)$ & $7(15 \%)$ & \\
\hline Other $(n=42)$ & $9(22 \%)$ & $11(26 \%)$ & $8(19 \%)$ & $14(33 \%)$ & \\
\hline \multicolumn{6}{|l|}{ SES } \\
\hline Higher $(n=52)$ & $9(17 \%)$ & $8(15 \%)$ & $16(31 \%)$ & 19 (37\%) & $0.251^{b}$ \\
\hline Lower $(n=91)$ & $20(22 \%)$ & $25(27 \%)$ & $21(23 \%)$ & $25(28 \%)$ & \\
\hline \multicolumn{6}{|l|}{ Age $(n=145)$} \\
\hline Mean (SD) & $16.7(1.3)$ & $17.1(1.2)$ & $17.3(1.1)$ & $17.6(1.0)$ & $0.032^{c}$ \\
\hline
\end{tabular}

${ }^{a}$ Substances include cigarette smoking, alcohol, and marijuana use in the last 12 months. 'Never used any' indicate those who never used any of the three substances in the last 12 months; 'Used only one', those that used any one substance; 'Used any two', those that used any two substances; 'Used all three', those that used all three substances in the last 12 months.

${ }^{b} \chi^{2}$ test of independence of substance use and demographic characteristics.

c t-test of independence of substance use and student age. 
Table 3 Multivariate associations between each substance and selected dietary practices in alternative high school students in the past 12 months $(N=145)$

\begin{tabular}{|c|c|c|c|c|c|c|c|c|c|}
\hline \multirow{3}{*}{ Dietary Intake } & \multicolumn{9}{|c|}{ Substance use in the past 12 months $^{a}$} \\
\hline & \multicolumn{3}{|c|}{$\begin{array}{l}\text { Cigarette Smoking } \\
\quad(n=144)\end{array}$} & \multicolumn{3}{|c|}{$\begin{array}{l}\text { Alcohol Use } \\
(n=144)\end{array}$} & \multicolumn{3}{|c|}{$\begin{array}{c}\text { Marijuana Use } \\
(n=145)\end{array}$} \\
\hline & $\begin{array}{l}\text { Estimate } \\
\text { (b) }\end{array}$ & $95 \% \mathrm{Cl}$ & $\begin{array}{c}\mathrm{p}- \\
\text { value }\end{array}$ & $\begin{array}{l}\text { Estimate } \\
\text { (b) }\end{array}$ & $95 \% \mathrm{Cl}$ & $\begin{array}{c}\mathrm{p}- \\
\text { value }\end{array}$ & $\begin{array}{l}\text { Estimate } \\
\text { (b) }\end{array}$ & $95 \% \mathrm{Cl}$ & $\begin{array}{c}\mathrm{p}- \\
\text { value }\end{array}$ \\
\hline Regular soda times/wk & 1.22 & $(0.25,2.2)$ & 0.019 & 0.79 & $(-0.78,2.39)$ & 0.295 & 1.05 & $(-0.14,2.25)$ & 0.093 \\
\hline Sports drinks times/wk & -0.08 & $(-0.79,0.63)$ & 0.972 & 0.03 & $(-1.12,1.20)$ & 0.847 & -0.41 & $(-1.28,0.45)$ & 0.838 \\
\hline $\begin{array}{l}\text { Other sugar-sweetened beverages times/ } \\
\qquad \text { wk }\end{array}$ & 0.77 & $\begin{array}{c}(- \\
0.05,1.61)\end{array}$ & 0.071 & 1.34 & $(0.02,2.67)$ & 0.079 & -0.08 & $(-1.10,0.94)$ & 0.893 \\
\hline Fast food restaurant times/wk & 0.26 & $(0.09,0.42)$ & 0.002 & 0.18 & $(-0.09,0.46)$ & 0.194 & 0.10 & $(-0.10,0.30)$ & 0.329 \\
\hline High-fat foods times/wk & 1.24 & $(0.07,2.41)$ & 0.037 & 2.61 & $(0.76,4.45)$ & 0.005 & 1.51 & $(0.10,2.92)$ & 0.035 \\
\hline Fruits/vegetables servings/day & 0.11 & $(-0.30,0.53)$ & 0.498 & -0.33 & $(-1.00,0.33)$ & 0.463 & -0.32 & $(-0.82,0.18)$ & 0.287 \\
\hline
\end{tabular}

${ }^{a}$ All estimates are adjusted for age, gender, race, and SES

multi-substance use was related to an unhealthful diet (beta range: -0.10 to -0.02) (Data not shown).

\section{Discussion and Conclusions}

This study described frequency of cigarette, alcohol, marijuana and multi-substance use and associations between each substance as well as multi-substance use and dietary practices, such as such as sugar-sweetened beverages, high-fat foods, fruits and vegetables, and frequency of fast food restaurant use among alternative high school students. Our results revealed that cigarette was the substance most frequently used by both males and females. Cigarette, alcohol and marijuana use were each associated with higher consumption of high-fat foods, and cigarette smoking was associated with higher consumption of regular soda and fast food restaurant use. Students who used multiple substances had progressively higher consumption of high-fat foods compared to nonusers and single substance users.
Daily smoking was more prevalent among this sample of alternative high school students (36\%) compared to a large socioeconomically and racially diverse sample of traditional high school students (14\%) [22] and to national surveillance data (10\%) [2].

Daily marijuana use among students was twice as high $(13 \%)$ as among traditional high school students participating in national surveys (6\%) [2]. In contrast, annual frequency of alcohol consumption in this sample (59\%) was similar to national surveillance data (61\%) [2]. The high prevalence of substance use in this study sample was also observed in other studies of alternative high school students [48-50]. According to the 2007 Minnesota Student Survey Alternative High Schools, frequency of any use of cigarette, alcohol or marijuana in the past 30 days was $61 \%, 57 \%$, and $47 \%$, respectively [50]. In contrast, statewide data of students attending traditional high schools indicated a rate for cigarette, alcohol, and marijuana use over the same period of $25 \%, 47 \%$, and $20 \%$, respectively [51].

Table 4 Mean dietary practices among alternative high school students by category of multi-substance use $(\mathrm{N}=145)$

\begin{tabular}{|c|c|c|c|c|c|}
\hline \multirow[b]{2}{*}{ Dietary Practices } & \multicolumn{5}{|c|}{ Number of Substances Used in the Past 12 Months * } \\
\hline & $\begin{array}{c}\text { Never Used } \\
\text { Mean (SE) } \\
\mathrm{n}=\mathbf{3 1}\end{array}$ & $\begin{array}{l}\text { Used any one } \\
\text { Mean (SE) } \\
n=33\end{array}$ & $\begin{array}{c}\text { Used any two } \\
\text { Mean (SE) } \\
\mathbf{n}=\mathbf{3 7}\end{array}$ & $\begin{array}{c}\text { Used all three } \\
\text { Mean (SE) } \\
n=44\end{array}$ & P Value \\
\hline Regular soda times/wk & $7.15(1.8)$ & $7.42(1.7)$ & $12.08(1.6)$ & $12.59(1.5)$ & 0.058 \\
\hline Sports drinks times/wk & $2.99(1.7)$ & $4.26(1.6)$ & $6.00(1.5)$ & $2.27(1.4)$ & 0.307 \\
\hline Other sugar-sweetened beverages times/wk & $5.01(1.8)$ & $7.28(1.8)$ & $8.44(1.7)$ & $8.34(1.6)$ & 0.400 \\
\hline Fast food restaurant times/wk & $2.05(0.33)$ & $3.04(0.3)$ & $2.93(0.2)$ & $2.92(0.2)$ & 0.113 \\
\hline High-fat foods times/wk & $18.23(2.2)^{a}$ & $30.07(2.1)^{b}$ & $25.41(2.0)^{b}$ & $29.17(1.9)^{b}$ & 0.0003 \\
\hline Fruits/vegetables servings/day & $2.94(0.8)$ & $3.82(0.8)$ & $4.21(0.7)$ & $2.98(0.7)$ & 0.728 \\
\hline
\end{tabular}

Sample size may vary across models due to missing responses. Mean values were adjusted for gender, race/ethnicity, SES, and age. $\mathrm{R}^{2}$ for base model ranged from 0.01 for fruits and vegetables to 0.19 for other sugar-sweetened beverages.

* Substances include cigarette smoking, alcohol, and marijuana use in the last 12 months. 'Never used any' indicate those who never used any of the three substances in the last 12 months; 'Used only one', those that used any one substance; 'Used any two', those that use any two substances; 'Used all three', those that used all three substances in the last 12 months.

$+\mathrm{P}$ value represents testing for differences in adjusted means of dietary practices by categories of multiple substance use $(\mathrm{df}=3)$.

$\otimes$ Include kool-aid, fruit drinks, lemonade or energy drinks.

${ }^{a b}$ Different superscripts indicate statistically significant differences between mean dietary practices by category of substance use. 
Table 5 Correlation matrix between the components (dietary practices) of the overall diet quality ${ }^{\mathrm{a}}$ of alternative high school students

\begin{tabular}{|c|c|c|c|c|c|c|}
\hline $\begin{array}{l}\text { Components of the diet } \\
\text { quality (dietary practices) }\end{array}$ & $\begin{array}{l}\text { Regular soda } \\
\text { times/wk }\end{array}$ & $\begin{array}{c}\text { Sports } \\
\text { drinks times/ } \\
\text { wk }\end{array}$ & $\begin{array}{c}\text { Other sugar-sweetened } \\
\text { beverages times/wk }\end{array}$ & $\begin{array}{c}\text { Fast food } \\
\text { restaurant times/ } \\
w k\end{array}$ & $\begin{array}{c}\text { High-fat } \\
\text { foods times/ } \\
\text { wk }\end{array}$ & $\begin{array}{c}\text { Fruits/vegetables } \\
\text { servings/day }\end{array}$ \\
\hline Regular soda times/wk & 1.0 & & & & & \\
\hline Sports drinks times/wk & 0.237 & 1.0 & & & & \\
\hline $\begin{array}{c}\text { Other sugar-sweetened } \\
\text { beverages times/wk }\end{array}$ & 0.331 & 0.595 & 1.0 & & & \\
\hline Fast food restaurant times/wk & 0.64 & 0.373 & 0.193 & 1.0 & & \\
\hline High-fat foods times/wk & 0.424 & 0.251 & 0.395 & 0.658 & 1.0 & \\
\hline Fruits/vegetables servings/day & 0.139 & -0.515 & -0.387 & -0.305 & -0.667 & 1.0 \\
\hline
\end{tabular}

${ }^{a}$ The overall impact of substance use on diet quality was assessed by treating the six dietary behaviors as correlated outcomes within individual. The repeated measures analysis of the six dietary behaviors estimates a single association of substance use on the overall diet quality. All sugar-sweetened beverages, high-fat food, and fast food restaurant use were reverse coded to represent a healthful diet quality.

Although studies show that frequency of substance use is higher among low compared to high SES populations, in our study it appears that the opposite was true. However, in our study, SES was labeled as 'lower' or 'higher' to indicate relative SES because of high prevalence of low income students in alternative high schools. Therefore, the labels do not denote 'high' or 'low' as this is true in other studies that measure SES with reported family income. The fact that in our study 'higher SES' students used slightly more substances than 'lower SES' may indicate that' higher SES' students might have the means to purchase these substances. Overall, the findings of this study agree with the literature indicating that alternative high school students smoke cigarettes and use marijuana more frequently compared to high school students participating in national studies.

Direct comparison of the frequency of multi-substance use cannot be made with other data, because of measurement differences [26]. However our results support the covariation of health-compromising behaviors as indicated by the high frequency of multi-substance use and its association with high-fat food intake among the students in this study. A study examining nutritionrelated behaviors and categories of substance use (highrisk, conventional, and abstainers) among 11-12 graders from an urban school district found high-risk substance users (combined use of PCP, heroin, crack/cocaine, cigarette, alcohol, or marijuana) to be eating at fast food and convenience stores more frequently than all the other groups [26]. Also, the association between cigarette smoking and consumption of regular soda, high-fat food, and fast food restaurant use in this sample is in agreement with other studies involving adolescents $[16,21,22,52]$. A study of a large racially and socioeconomically diverse group of adolescents showed that those who smoked had higher soda and fast food consumption [22].

In a separate analyses for each substance, we also found associations between alcohol and marijuana use and high-fat food intake. A study using data from a statewide survey also found use of cigarette, alcohol, and marijuana to be individually associated with an unhealthful diet among middle and high school students [13]. Previous studies with adolescents have reported inverse associations of cigarette smoking with fruit and vegetable consumption [22-25], but our findings did not support these associations, which may partly be due to measurement differences. In the present study, the 6item questionnaire was used to measure usual intake of fruits and vegetables over the past year. Compared with the 24-hour dietary recalls, the 6-item questionnaire performed equally to the Harvard Food Frequency Questionnaire [43]; however the lack of variability in fruit and vegetable intake by the students in the current study and the relative small sample may not have been sufficient to detect significant differences in dietary practices by each category of substance use.

One of the strengths of this study was its diverse sample of adolescents with respect to gender, race/ethnicity and SES. The measures of dietary practices and substance use have been previously tested in other adolescent populations. This study is the first to examine associations between categories of multiple substance use and dietary practices among alternative high school students. Although the student participation rate was lower than desired, the demographic distribution of our sample closely resembles the demographic characteristics of the students in the study schools (male $=51 \%$; black $=42 \%$, white $=39 \%$; low SES $=56 \%$ ). A limitation of the study may be the introduction of selection bias. Although all students were invited to participate in the measurements, students who were absent or decided not to participate may differ from the ones who participated, in regard to substance use and dietary practices. The study utilized a cross-sectional analysis that only considers the associations between correlate and outcome variables. Given the relatively small sample size and that participants in this study represent only the 
Twin Cities area of Minnesota, the generalizability of the findings is limited.

In conclusion, consistent with findings from other studies with alternative high school students, our findings support the high rate of co-occurrence of health-compromising behaviors. As previous studies indicate, behavioral risk factors that contribute to chronic disease begin in adolescence and continue into young adulthood [16,53-55], indicating that the age of initiation significantly predicts substance use and frequency later in life. For example, consistent positive associations have been observed between alcohol use in adolescence and smoking in young adulthood and between younger age of smoking initiation and increased smoking frequency in young adulthood $[56,57]$. Although alternative high school students are particularly vulnerable to engaging in behaviors that compromise their health, studies about substance use and dietary practices among this population are few. Findings from this research will contribute to the limited body of literature regarding the link between substance use and dietary practices and can set the stage for larger studies on co-variation of health compromising behaviors among alternative high school students. Alternative high schools are ideal settings to reach at-risk youth at an early age, who will greatly benefit from comprehensive and targeted health interventions.

\section{Acknowledgements}

This research was supported by a grant from NIH/NIDDK R21DK072948. It was also supported in part by the Adolescent Health Protection Program grant number T01-DP000112 from the Centers for Disease Control and Prevention (CDC). Its contents are solely the responsibility of the authors and do not necessarily represent the official views of the CDC. We gratefully thank the school staff and students who participated in the Team COOL pilot study.

\section{Author details}

${ }^{1}$ University of Minnesota, Division of Epidemiology and Community Health, School of, Public Health, 1300 South 2nd Street, Suite 300, Minneapolis, MN 55454, USA. 'University of Minnesota, School of Nursing, Room 5-140 WDH 1331, 308 Harvard St S E, Minneapolis, MN 55455, USA.

\section{Authors' contributions}

CA collected data, analyzed and interpreted the data, and led the writing and revisions of the manuscript. MYK conceptualized the study, collected data, assisted with data interpretation and critically edited the manuscript. JAF collected data, assisted with data analysis and critically edited the manuscript. PJH assisted with data analysis and critically edited the manuscript. MS assisted in the conceptualization of the study and critically edited the manuscript. All authors read and approved the final manuscript.

\section{Competing interests}

The authors declare that they have no competing interests.

Received: 4 May 2010 Accepted: 25 April 2011 Published: 25 April 2011

\section{References}

1. Centers for Disease Control and Prevention: Youth Risk Behavior Surveillance. Surveillance Summaries 2009. MMWR 2010, 59, (No. SS-5).
2. Johnston LD, O'Malley PM, Bachman JG, Schulenberg JE: Monitoring the Future national results on adolescent drug use: Overview of key findings 2008 Bethesda, MD: National Institute on Drug Abuse; 2009, (NIH Publication No. 09-7401).

3. Draus JM, Santos AP, Franklin GA, Foley DS: Drug and alcohol use among adolescent blunt trauma patients: dying to get high? J Pediatr Surg 2008, 43:208-211.

4. Englund MM, Egeland B, Oliva EM, Collins WA: Childhood and adolescent predictors of heavy drinking and alcohol use disorders in early adulthood: a longitudinal developmental analysis. Addiction 2008, 103(Suppl 1):23-35.

5. Orr OS, James SA, Reiter JP: Unintended Pregnancy and Prenatal Behaviors Among Urban, Black Women in Baltimore, Maryland: The Baltimore Preterm Birth Study. Ann Epidemiol 2008, 18:545-551.

6. Rudatsikira E, Muula AS, Siziya S: Variables associated with physical fighting among US high-school Students. Clin Pract Epidemiol Ment Health 2008, 4:16.

7. Muula AS, Rudatsikira A, Siziya S: Correlates of weapon carrying among high school students in the United States. Ann Gen Psych 2008, 7:8.

8. Melzer-Lange MD: Violence and associated high-risk health behavior in adolescents. Substance abuse, sexually transmitted diseases, and pregnancy of adolescents. Pediatr Clin N Am 1998, 45(2):307-317.

9. U.S. Department of Health and Human Services: Healthy People 2010: Understanding and Improving Health. Washington, DC: U.S. Government Printing Office, November; 22000.

10. Schlecht NF, Franco EL, Pintos J, Negassa A, Kowalski LP, Oliveira BV, Curado MP: Interaction between tobacco and alcohol consumption and the risk of cancers of the upper aero-digestive tract in Brazil. Am J Epidemiol 1999, 150:1129-37.

11. Feskanich D, Ziegler RG, Michaud DS, Giovannuci EL, Speizer FE, Willett WC, Golditz GA: Prospective Study of Fruit and Vegetable Consumption and Risk of Lung Cancer Among Men and Women. J Natl Cancer Inst 2000, 92:1812-23.

12. Weisburger JH: Eat to live, not live to eat. Nutrition 2000, 16:767-773.

13. NeumarkSztainer D, Story M, Toporoff E, Himes JH, Resnick MD, Blum R: Covariations of eating behaviors with other health-related behaviors among adolescents. J Adolescent Health 1997, 20:450-458.

14. Grunbaum JA, Lowry R, Kann L: Prevalence of health-related behaviors among alternative high school students as compared with students attending regular high schools. J Adolescent Health 2001, 29(5):337-343.

15. Pronk PN, Anderson HL, Crain A, Martinson BC, O'Connor PJ, Sherwood NE, Whitebird RR: Meeting recommendations for multiple healthy lifestyle factors. Prevalence, clustering and predictors among adolescents, adult, and senior health plan members. Am J Prev Med 2004, 27(2S):25-33.

16. Kvaavik $\mathrm{E}$, Andersen FL, Klepp Kl: The stability of soft drink intake from adolescence to adult age and the association between long-term consumption of soft drinks and lifestyle factors and body weight. Public Health Nutr 2005, 8(2):149-157.

17. Donovan JE, Jessor R, Costa FM: Structure of health-enhancing behavior in adolescence: A latent-variable approach. J Health Soc Behav 1993, 34:346-362.

18. Pronk N, Wing R: Physical activity and maintenance of long-term weight loss. Obes Res 1994, 2:587-99.

19. Fine LJ, Philogene GS, Gramling R, Coups EJ, Sinha S: Prevalence of multiple behavioral chronic disease risk factors in the United States: Results from the 2001 National Health Interview Survey. Am J Prev Med 2004, 27(suppl 1):18-24.

20. Schuit JA, van Loon MJ, Tijhuis M, Ocke CM: Clustering of lifestyle risk factors in general adults population. Prev Med 2002, 35:219-224.

21. Burke V, Milligan RAK, Beilin JL, Dunbar D, Spencer M, Balde E, Gracey MP. Clustering of health-related behaviors among 18-year-old Australians. Prev Med 1997, 26:724-733.

22. Larson IN, Story M, Perry LC, Neumark-Sztainer D, Hannan PJ: Are diet and physical activity patterns related to cigarette smoking in adolescents? Findings from Project EAT. Prev Chronic Dis [serial online] 2007 [http:// www.cdc.gov/pcd/issues/2007/jul/06_0053.htm], Accessed on 8/2/2008.

23. Wilson DB, Smith BN, Speizer IS, Bean MK, Mitchell KS, Uguy LS, Fries EA: Differences in food intake and exercise by smoking status in adolescents. Prev Med 2005, 40(6):872-9.

24. Wilson DB, Nietert JP: Patterns of fruit, vegetable, and milk consumption among smoking and nonsmoking female teens. Am J Prev Med 2002, 4: 240-246. 
25. Neumark-Sztainer D, Story M, Resnick M, Blum RW: Correlates of inadequate fruit and vegetable consumption among adolescents. Prev Med 1996, 25:497-505.

26. Benedict J, Evans W, Calder JC: An exploratory study of recreational drug use and nutrition-related behaviors and attitudes among adolescents. J Drug Education 1999, 29(2):139-155.

27. Henry K: Who's skipping school: Characteristics of truants in $8^{\text {th }}$ and $10^{\text {th }}$ grade. J Sch Health 2007, 77:29-35.

28. Ellickson PL, Tucker SJ, Klein DJ: High-Risk Behaviors Associated With Early Smoking: Results From a 5-Year Follow-Up. J Adolescent Health 2001, 28:465-473.

29. Ellickson P, Saner H, McGuigan K: Profiles of Violent Youth: Substance Use and Other Concurrent Problems. Am J Public Health 1997, 87:985-991.

30. Bray JW, Zarkin GA, Ringwalt C, QI J: The relationship between marijuana initiations and dropping out of high school. Health Econ 2000, 9:9-18.

31. Kleiner B, Porch R, Farris E: Public alternative schools and programs for students at risk of education failure: 2000-01. (NCES 2002-04). U.S. Department of Education. National Center for Education Statistics Washington, DC; 2002.

32. Scarinci IC, Robinson LA, Alfano CM, Zbikowski SM, Klesges RC: The relationship between socioeconomic status, ethnicity and cigarette smoking in urban adolescents. Prev Med 2002, 34:171-178.

33. Weller NF, Tortolero SR, Kelder SH, Grunbaum JA, Carvajal SC, Gingiss PM: Health risk behavior of Texas students attending dropout prevention/ recovery schools in 1997. J Sch Health 1999, 1: 22-28.

34. Basen-Engquist K, Grunbaum JA: Comparison of health risk behaviors between students in a regular high school and students in an alternative high school. J Sch Health 1993, 63(10):421+.

35. Arcan C, Kubik MY, Fulkerson J, Story M: Sociodemographic differences in selected eating practices among alternative high school students. J Am Diet Assoc 2009, 109:823-829.

36. Sirard JR, Kubik MY, Fulkerson JA, Arcan C: Objectively measured physical activity in urban alternative high school students. Med Sci Sports Exerc 2008, 40(12):2088-95

37. Kubik MY, Lytle L, Fulkerson AJ: Physical activity, dietary practices, and other health behaviors of at-risk youth attending alternative high schools. J Sch Health 2004, 74(4):119-124.

38. McLeroy K, Bibeau D, Steckler A, Glanz K: An ecological perspective on health promotion programs. Health Education Quarterly 1988, 15(4):351-377.

39. Kubik MY, Davey C, Fulkerson J, Sirard J, Story M, Arcan C: Alternative high school students: Prevalence and correlates of overweight. Am J Health Behav 2009, 33(5):600-609.

40. Minnesota Department of Education. 2007 [http://education.state.mn.us/ MDE/Data/Data_Downloads/School_and_District/index.html], Accessed: September 10

41. Grimm GC, Harnack L, Story M: Factors associated with soft drink consumption in school-aged children. J Am Diet Assoc 2004, 104:1244-9.

42. Neumark-Sztainer D, Story M, Hannan PJ, Rex J: New Moves: a schoolbased obesity prevention program for adolescent girls. Prev Med 2003, 37:41-51.

43. Block G, Gillespie C, Rosenbaum HE, Jenson C: A rapid food screener to assess fat and fruit and vegetable intake. Am J Prev Med 2000, 18(4):284-288

44. Field A, Colditz G, Fox KM, Byers T, Serdula M, Bosch RJ, Peterson KE: Comparison of 4 Questionnaires for Assessment of Fruit and Vegetable Intake. Am J Public Health 1998, 88(8):1216-1218.

45. Brener ND, Kann L, McManus T, Kinchen SA, Sundberg EC, Ross JG: Reliability of the 1999 Youth Risk Behavior Survey Questionnaire. J Adolescent Health 2002, 31:336-342.

46. Sherwood NE, Wall M, Neumark-Sztainer D, Story M: Effect of socioeconomic status on weight change patterns in adolescents. Prev Chronic Dis 2009, 6(1) [http://www.cdc.gov/pcd/issues/2009/jan/07_0226. htm], Accessed 10/5/2010.

47. Murray DM: Design and analysis of group-randomized trials. New York: Oxford University Press; 1998

48. Grunbaum JA, Kann L, Kinchen SA, Ross JG, Gowda VR, Collins JL, Kolbe LJ: Youth Risk Behavior Surveillance National Alternative High School Youth Risk Behavior Survey, United States, 1998. J Sch Health 2000, 70(1):5-17.

49. Denny SJ, Clark TC, Watson PD: Comparison of health-risk behaviours among students in alternative high schools from New Zealand and the USA. J Paediatr Child Health 2003, 39:33-39.
50. Minnesota Student Survey 2007. Alternative Schools and Area Learning Centers. Minnesota Center for Health Statistics, Minnesota Department of Health; 2007.

51. Minnesota Student Survey 2007. Statewide tables; 2007.

52. Subar F, Harlan C, Mattson E: Food and nutrient intake differences between smokers and non-smokers in the U.S. Am J Public Health 1990, 80:1323-1329, 11.

53. Kelder SH, Perry CL, Klepp Kl, Lytle LL: Longitudinal tracking of adolescent smoking, physical activity, and food choice behaviors. Am J Public Health 1994, 84:1121-1126.

54. Lien N, Lytle LA, Klepp KI: Stability in consumption of fruit, vegetables, and sugary foods in a cohort from age 14 to age 21. Prev Med 2001, 33:217-26.

55. Cullen WK, Koehly ML, Anderson C, Baranowski T, Prokhorov A, BasenEngquist K, Wetter D, Hergenroeder A: Gender differences in chronic disease risk behaviors through the transition out of high school. Am J Prev Med 1999, 17(1):1-7.

56. Paavola M, Vartiainen E, Haukkala A: Smoking, alcohol use, and physical activity: A 13-year longitudinal study ranging from adolescence into adulthood. J Adolescent Health 2004, 35:238-244.

57. Everett SA, Warren CW, Sharp D, Kann L, Husten CG, Crossett L: Initiation of cigarette smoking and subsequent smoking behavior among U.S high school students. Prev Med 1999, 29:327-333.

\section{Pre-publication history}

The pre-publication history for this paper can be accessed here: http://www.biomedcentral.com/1471-2458/11/263/prepub

\section{doi:10.1186/1471-2458-11-263}

Cite this article as: Arcan et al:: Substance use and dietary practices among students attending alternative high schools: results from a pilot study. BMC Public Health 2011 11:263.

\section{Submit your next manuscript to BioMed Central and take full advantage of:}

- Convenient online submission

- Thorough peer review

- No space constraints or color figure charges

- Immediate publication on acceptance

- Inclusion in PubMed, CAS, Scopus and Google Scholar

- Research which is freely available for redistribution

Submit your manuscript at www.biomedcentral.com/submit
Biomed Central 